\title{
DETECTION OF CONCRETE DAMAGE USING ULTRASONIC PULSE VELOCITY METHOD
}

\author{
Manish Dogra ${ }^{1 *}$, Pankaj Jain ${ }^{2}$ \\ ${ }^{* 1}$ Manager at Ireo Pvt. Ltd., ${ }^{2}$ AGM at Ireo Pvt. Ltd.
}

*Corresponding Author: -

\begin{abstract}
: -
Ultrasonic Pulse Velocity (UPV) method is used to detect cracks and flaws inside the concrete structure. There are two types of simulated cracks, namely, cracks perpendicular to axis of element and cracks parallel to axis of element were induced without breaking them. The method can be used to measure the depth of vertical cracks. The degree of accuracy is high, if the distance is maintained between 100 - $200 \mathrm{~mm}$. However, for measuring horizontal cracks, this method does not give the result with high degree of accuracy. But within a distance of 100-200 $\mathrm{mm}$ between the transducers, the depth of the horizontal cracks can be estimated to a reasonable degree of accuracy. Hence, the distance between the transducers plays an important role degree of accuracy of measuring depth.
\end{abstract}

\section{(c) $(\$)$}




\section{INTRODUCTION}

The ultrasonic pulse velocity is used for determination of crack depth in concrete structure. The test instrument consists of an element of producing and introducing a pulse into the concrete structure (pulse generator and transmitter), and a means of measuring the time taken by the pulse to travel through the concrete member.

Piezoelectric sensors are placed at opposite sides of the concrete member. Electronic pulses are generated by the sensors and the time taken by the pulse to travel through the concrete member is measured by the other sensor. As we Know the distance traveled by the pulse, propagation velocity can be easily measured and based on the velocity, condition of the concrete is determined.

\section{MeThodology A) Mixture Proportions}

OPC 43 Grade cement is used for the experiment. $25 \mathrm{~mm}$ and $12.5 \mathrm{~mm}$ maximum sized coarse aggregates were used for Normal concrete (NC) and self-compacting concrete (SCC) respectively. SCC mixes were used in order to simulate horizontal cracks with ease. River sand with a fineness modulus of 2.10 were used. Fly ash and super plasticizer was used in the SCC mixture. Viscosity modifying agents were also used to avoid segregation in SCC mixes. The mixture proportions for the above said mixtures are given in table below.

Table 1: Mixture Proportions (Note: the weights shown are in $\mathrm{kg}$ per 100kg of concrete)

\begin{tabular}{|l|c|c|}
\hline $\begin{array}{l}\text { Mixture } \\
\text { designation } \\
\text { Ingredients }\end{array}$ & $\begin{array}{l}\text { Normal } \\
\text { Concrete }\end{array}$ & $\begin{array}{c}\text { Self } \\
\text { Compacting } \\
\text { Concrete }\end{array}$ \\
\hline Cement & 13.33 & 16.3 \\
\hline River sand & 26.67 & 35.5 \\
\hline $25 \mathrm{~mm}$ Aggregate & 53.33 & 0 \\
\hline $12.5 \mathrm{~mm}$ aggregate & 0 & 28.7 \\
\hline Water & 6.67 & 8.7 \\
\hline Fly ash & 0 & 10.3 \\
\hline Glenium 51 & 0 & 0.20 \\
\hline VMA & 0 & $8 \times 10-4$ \\
\hline
\end{tabular}

- Beam dimensions - 100mm x 100mm x 500mm

- Cube dimensions - 150mm x 150mm x $150 \mathrm{~mm}$

The specimens were kept in curing tank for a period of 7 days.

\section{B) Crack Simulation in Concrete Simulation of Vertical Crack}

An ideal vertical crack was simulated in a beam by a diamond tipped concrete cutter perpendicular to the axis of the beam to different depths. A real crack was simulated in the beam by using a thin sheet of plastic ( $1 \mathrm{~mm}$ thick) while casting the beam

\section{Simulation of Horizontal Crack}

Materials with acoustic impedance (table 2) much lesser than that of concrete were used to simulate the horizontal cracks. Materials used in this experiment are:

i) Thermocole

ii) PVC (Poly Vinyl Chloride)

\section{EXPERIMENTAL STUDY}

The ultrasonic pulse transmits a small amount of energy by the air. Then, if an ultrasonic pulse traveling through the concrete member crosses a void whose projections are perpendicular to the path length is larger than the area of the transmitting transducer; the pulse will get diffracted from its actual path. Thus, the time taken by the pulse will be greater than that through a similar concrete without any defect. Hence pulse velocity method is effective in locating cracks, cavities, voids and other such defects in concrete members.

\section{Measuring depth of vertical crack}

The depth, h, is given by equation (1),

$$
\mathrm{h}=\left(\mathrm{x} / \mathrm{T}_{2}\right)\left(\mathrm{T}_{1}^{2}-\mathrm{T}_{2}^{2}\right)^{2}
$$

$\mathrm{x}=$ distance of transducer from the crack (note that both transducers must be placed equidistant from the crack);

$\mathrm{T}_{1}=$ transmit time around the crack

$\mathrm{T}_{2}=$ transmit time along the surface of the same type of concrete without any crack (note that surface path length for T1 and T2 must be equal). 


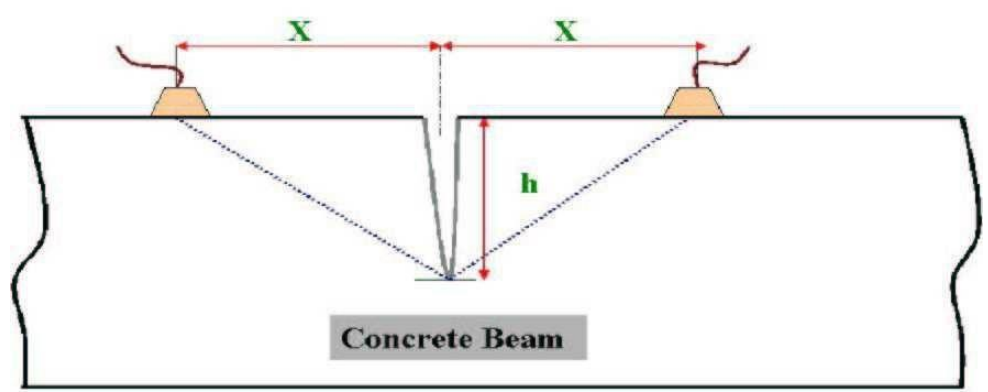

Fig.1: Vertical crack depth estimation

The above said equation is valid only when the crack is perpendicular to the concrete surface. A check should be made to determine if the crack is perpendicular to the surface or not. This can be done as follows Place both the transducers equidistant from the crack and obtain the transit time. Move each transducer, in turn, away from the crack. If the transmit time decreases, then the crack slopes towards the direction in which transducer was moved.

Table 2: Measurement of Crack depths on beam

\begin{tabular}{|l|l|l|l|l|l|}
\hline S.No. & $\begin{array}{l}\text { Depth of } \\
\text { actual crack }\end{array}$ & $\mathrm{x}$ & $\mathrm{T} 1$ & $\mathrm{~T} 2$ & $\begin{array}{l}\text { Crack depth } \\
\text { measured }\end{array}$ \\
\hline & $(\mathrm{cm})$ & $(\mathrm{cm})$ & $(\mathrm{s})$ & $(\mathrm{s})$ & $(\mathrm{cm})$ \\
\hline 1. & 4.1 & 10 & 95.6 & 75.8 & 7.68 \\
\hline 2. & 4.1 & 20 & 189.5 & 152.9 & 14.64 \\
\hline
\end{tabular}

\section{Measuring depth of horizontal cracks}

The transmitter is fixed at a point and the position of the receiver is changed every time. The travel time of the pulse wave is recorded. Knowing the velocity of the pulse wave (compression wave) through the concrete the depth of the horizontal crack can be estimated from the equation (2),

$$
y=05 \quad\left(V^{2} T^{2}-x^{2}\right)
$$

Where

$\mathrm{y}=$ depth of the horizontal crack

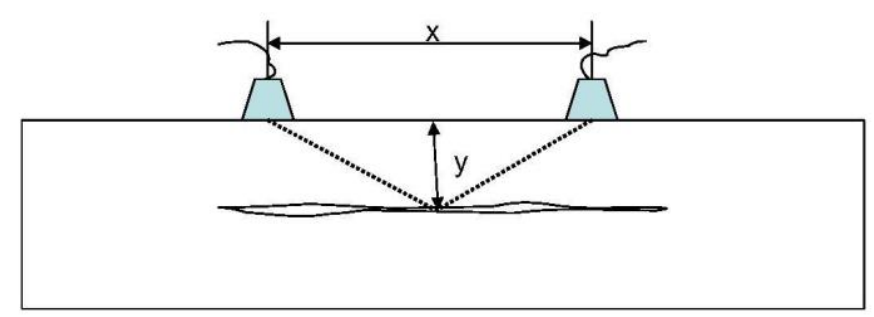

Fig.2: Experimental set-up for horizontal crack depth estimation

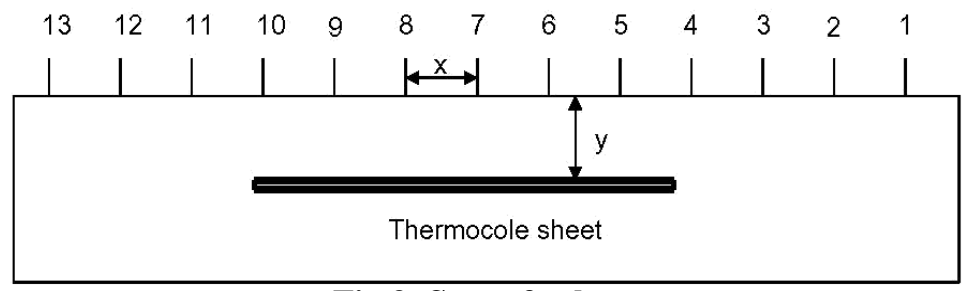

Fig.3: Setup for beam

$\mathrm{V}=$ velocity of the compression wave through the concrete; $\mathrm{x}=$ distance between the two transducers; $\mathrm{T}=$ transit time.

It should be noted that if the distance between the two transducers is small, the surface wave will reach the receiver before the compression wave. Therefore, a minimum distance $(150 \mathrm{~mm}-200 \mathrm{~mm}$ ) should be maintained between the transmitter and the receiver to ensure that the wave reaching the receiver is a compression wave. 
Table 3: Measurements of depth of horizontal crack in beam

\begin{tabular}{|l|c|c|c|c|}
\hline S.No. & Pts & $\mathrm{x}(\mathrm{cm})$ & $\mathrm{t}(: \mathrm{s})$ & $\mathrm{y}(\mathrm{cm})$ \\
\hline 1 & $1-2$ & 5 & 16.2 & - \\
\hline 2 & $1-3$ & 10 & 36.6 & - \\
\hline 3 & $1-4$ & 15 & 56.5 & - \\
\hline 4 & $1-5$ & 20 & 70.3 & - \\
\hline 5 & $1-6$ & 25 & 98.7 & - \\
\hline 6 & $1-7$ & 30 & 112.3 & - \\
\hline 7 & $1-8$ & 35 & 128.9 & - \\
\hline 8 & $1-9$ & 40 & 144.3 & - \\
\hline 9 & $1-10$ & 45 & 195.5 & 51.6 \\
\hline 10 & $4-5$ & 5 & 16.7 & 56.96 \\
\hline 11 & $4-6$ & 10 & 41.9 & 101.84 \\
\hline 12 & $4-7$ & 15 & 54.9 & 113.44 \\
\hline 13 & $4-8$ & 20 & 83.2 & 122.25 \\
\hline 14 & $4-9$ & 25 & 98.4 & 112.8 \\
\hline 15 & $4-10$ & 30 & & - \\
\hline
\end{tabular}

\section{CONCLUSION}

a) Vibration behavior of beam is very sensitive to crack location, crack depth, crack depth and mode number. Frequency decreases largely with the increase in crack depth and mode number but incase of crack location it also depends on boundary and conditions.

b) Result slightly deviate from the actual parameters due to variation in the analytical and experimental frequencies which are in turn due to assumptions about damping.

c) It is also seen that error in crack location is more than the crack depth. we are getting more accurate result in the severity cases which are actually more relevant than location a this helps result in the severity cases which are actually more relevant than location as this helps us to decide whether to repair it or not.

d) The study can be extended by incorporating the error i.e by taking the mean of the error between experimental and analytical modal frequency values for varying crack depths and crack location and thereby reducing it from the analytical value. This will help to get the result in the practical cases and will give the results in the vicinity of the damage. These will greatly reduce the labour, time and cost making it effective in use .

e) The cantilever and simply supported cracked beams can also be analysed using this method . but incase of cantilever and simply supported beams the error between of boundary stiffnesses between analytical results will be more due to variation of boundary stiffnesses between analytical and experimental, so error incorporation gives better results.

f) This method can be extended to beams with multiple cracks.

\section{REFERENCES}

[1].Deokar A.A.V, Wakchaure B.V.D, “ Experimental Investigation Of Crack Detection in Cantilever Beam Using Natural Frequency as Basic Criteriaion”, International Conference on Current Trends IN Technology , Nuicone (2011)

[2].Khiem N.T ., “A simplified method for natural frequency analysis of a multiple cracked beam " Journal of Sound and Vibration ., 245(2001)pp.737-751.

[3].Chaudhari T.D ., Modelling of transverse vibration of beam of linearly variable depth with edge crack ",Engineering Fracture Mechanics 63 (1999), pp.425-445.

[4].Dimarogonas A.D, “ Vibration of cracked structures: a state of the art review Engineering Fracture Mechanics., 55 (1996)pp.831-857.

[5].Nahvi H., jabbari M., :Crack detection in beams using experimental modal data and finite element model ", journal of Mechanical Science and Technology., vol. 24(3)(2010).pp.801-804.

[6].Lee J, "Identification of crack in a beam by the boundry element method “ , Journal of Mechanical Science and Technology .,vol. 24(3)(2010).pp801-804 